\title{
The effect of sleep disturbance on the association between chronic medical conditions and depressive symptoms over time
}

\author{
Amanda Leggett University of Michigan, Ann Arbor, MI, US \\ leggetta@med.umich.edu \\ Shervin Assari University of Michigan, Ann Arbor, MI, US \\ Sarah Burgard University of Michigan, Ann Arbor, MI, US \\ Kara Zivin University of Michigan and Department of Veterans' Affairs, US
}

(Received November $2016 \quad$ Revised February 2017) http://dx.doi.org/10.14301/llcs.v8i2.433

\section{Abstract}

Chronic medical conditions (CMC) and sleep disturbances are common among adults and associated with depression. We tested sleep disturbance as a moderator of the effect of CMC on depressive symptoms. The sample includes 3597 adults surveyed up to five times over 25 years (1986-2012) from the nationally representative American's Changing Lives Study (ACL). A multi-level model was estimated to examine sleep disturbance as a moderator of the CMC and depressive symptom association, with a second interaction tested for age as a moderator of the within-person level variability in CMC and depressive symptom association. Sleep disturbance and CMC were associated with depressive symptoms at the between-person level, while only sleep disturbance was associated with depressive symptoms at the within-person level. Sleep disturbance significantly interacted with CMC such that more CMCs were associated with more depressive symptoms among individuals sleeping well, but poor sleep was associated with worse depression regardless of CMC. A second interaction between age and within-person variability in CMC was found significant, suggesting that younger adults had higher symptoms of depression at times of below average CMC relative to older adults. The effect of CMC on depressive symptoms may depend on sleep as well as age. Sleeping restfully may allow individuals with CMC the rejuvenation needed to cope with illness adaptively.

\section{Keywords}

Chronic medical conditions, sleep disturbance, depressive symptoms, moderation 


\section{Introduction}

Chronic medical conditions (CMCs) are of increasing concern and burden as individuals age. The proportion of the population reporting multiple CMCs ranges from approximately $21 \%$ of the general adult population to over $60 \%$ among older adults (Vogeli et al., 2007). By 2030, an estimated half of the population will have at least one CMC (Anderson, 2010). While advancing treatments for CMCs have led to a decline in risk of associated mortality, individuals are now living longer with these CMCs, and health care utilisation and costs increase significantly with each additional CMC (Lehnert et al., 2011). An added problem is that CMCs increase risk for and are commonly comorbid with mental illnesses such as depression (Bhattarai, Charlton, Rudisill, \& Gulliford, 2013; Egede, 2007; Moussavi et al., 2007). Given the association between depressive symptoms and CMCs, determining ways to intervene and improve mental health among these individuals has the potential to enhance quality of life, and reduce overall healthcare costs. The current study explores whether sleep disturbance compounds the effect of $\mathrm{CMC}$ on depression and thereby may be a key target for intervention among individuals with CMC.

\section{Mental health consequences of chronic medical conditions}

Some researchers have suggested that depression would be less common in later life if not for declines in health that put individuals at increased risk for the disorder (Schnittker, 2005). Moussavi et al. (2007) found as many as $23 \%$ of individuals with a physical $\mathrm{CMC}$ also had depression, significantly more than the comparison population without a CMC (3.2\%). In another study the 12-month prevalence of major depressive disorder ranged from $8 \%$ to $17 \%$ among adults with different CMCs, and relative to those without chronic medical conditions, those with a chronic condition and depression had greater odds of emergency room and ambulatory visits, time in bed due to illness, and functional impairment (Egede, 2007). The relative rate of depression increased significantly with an increasing number of morbidities (ex. relative rate ratio of 1.63 for one condition versus 2.35 for 3 conditions) (Bhattarai et al., 2013). In prospective evidence, onset of a long-term depressive episode was predicted by having CMCs and limitations in activities of daily living due to health problems (Geerlings, Beekman, Deeg, \& Van Tilburg, 2000). The current study adds to this evidence by taking a life-course developmental approach to consider whether the number of CMCs, as well as within-person variability in multimorbidity over time, is associated with depressive symptoms.

Chronic conditions may be associated with depression for a number of reasons. Depression may result from an individual's psychological response to developing a chronic condition, may be a symptom, complication, or functional impairment that results from the chronic condition, may be a side effect of a medication prescribed to treat a chronic medical conditions, and/or may stem from a pathophysiologic effect of the chronic condition (e.g. inflammation) (Katon, 2003; Konsman, Parnet, \& Dantzer, 2002; Ormel, Rijsdijk, Sullivan, van Sonderen, \& Kempen, 2002). The theory of vascular depression, for example, posits that cerebrovascular diseases alter brain structure and function, thereby leading to depression (Alexopoulos et al., 1997). Additionally, sleep disturbance may reduce one's energy and capacity to adaptively cope with one's medical condition, and thereby moderate the association between $\mathrm{CMC}$ and depression.

\section{Sleep as a potential moderator}

Disturbed sleep has also been identified as a contributing factor to the development and expression of depression (Baglioni et al., 2011; Maglione et al., 2012). For example, non-depressed individuals with insomnia have a two-fold increased risk of subsequently developing depression (Baglioni et al., 2011). Even among individuals without an insomnia diagnosis but with insomnia symptoms, the mean subsequent incidence of depression from a meta-analysis of nine studies with mixed age samples was $13.1 \%$ compared to only $4 \%$ among individuals without sleep problems. Sleep disturbances are highly prevalent in individuals with CMCs, and are associated with decrements in health-related quality of life (Katz \& McHorney, 2002). In a communitydwelling sample of adults, $44.1 \%$ of individuals with heart disease reported chronic insomnia compared to 
only $22.8 \%$ of those without heart disease (Taylor et al., 2007).

Disturbed sleep is likely a disruptive symptom and outcome of many CMCs, and may be an ailment that individuals face as a side effect of treatment for their illness. For example, insomnia is commonly experienced by individuals with cancer and is considered one of the most distressing symptoms (Ann M Berger, 2009; Ann Malone Berger \& Mitchell, 2008; Bower, 2008; Carpenter et al., 2004; Wielgus, Berger, \& Hertzog, 2009). Work by Devins et al. (1993) found that restless sleep in individuals with $\mathrm{CMC}$ was associated with illness intrusiveness, defined as the inability to partake in desired activities due to one's illness, and suggested that this may account for some of the association between sleep and depression in individuals with CMC. On its own, poor sleep is also associated with malaise and exhaustion (Parish, 2009), which may make illness management more difficult. Longitudinal studies and clinical trials also suggest that the association between sleep disturbance and pain may be bidirectional, further challenging how individuals may manage and adapt to CMCs. Pain can disturb one's sleep, and likewise, disturbed sleep may intensify pain (Smith \& Haythornthwaite, 2004). When someone is sleeping restlessly, they may not be able to manage a CMC as well as those who are maintaining restorative sleep (Hamilton, Catley, \& Karlson, 2007). Sleep disturbance, therefore, is directly and negatively related to mental health, and our study uniquely tests whether sleep disturbance may also compound the effect of CMCs on depression by reducing the body's ability to adaptively respond to, cope with, and recover from chronic medical conditions (Hamilton et al., 2007).

\section{Age and illness}

As a second aim we consider whether an individual's age interacts with variability in one's level of $\mathrm{CMC}$ in predicting depressive symptoms. As we examine both the mean level of $\mathrm{CMC}$ and an individual's variability around his/her mean, age is important to consider as a time with less CMC is likely a time where an individual is younger, given the cumulative pattern of CMC. Further, prior research suggests that whether a stressor occurs at an appropriate developmental time, as opposed to a less expected time, relates to its level of impact (Sherbourne, Meredith, Rogers, \& Ware, 1992). A younger adult experiencing a CMC may suffer more stress due to its unexpected nature, on the other hand an older adult may experience greater disability from the illness. Additionally older adults tend to use different coping strategies in the face of stress - such as appraising stressors more positively than younger adults and using distancing strategies (Berg \& Upchurch, 2007; Brandtstädter \& Greve, 1994; Diehl, Coyle, \& Labouvie-Vief, 1996; Felton \& Revenson, 1987; Folkman, Lazarus, Pimley, \& Novacek, 1987; Heckhausen \& Schulz, 1995).

\section{The current study}

Utilising a longitudinal multi-level approach and multiple observations nested within each respondent, in the current study we first consider chronic medical conditions and sleep disturbance as independent covariates of depressive symptoms over time in a nationally representative sample of US adults. Associations between sleep disturbance, CMCs and depression have been well established; however our longitudinal model furthers this work by examining how sleep disturbance and CMCs vary over time and whether individual variation in these factors is associated with changes in depressive symptoms. Second, our main focus is to examine whether sleep disturbance acts as moderator of the effect of CMCs on depressive symptoms. This aim is in line with studies which have shown a moderating impact of sleep on various risk factors in association with depression and psychological strain, and extends prior work which has looked at the main effects of CMCs and sleep disturbance on depression by considering potential moderation (Leggett, Burgard, \& Zivin, 2016; Sanz-Vergel, Demerouti, Mayo, \& Moreno-Jiménez, 2011). Finally as a second aim we consider whether there is an interaction between age and an individual's variability in CMCs in association with depressive symptoms.

\section{Methods}

Data are drawn from the nationally representative Americans' Changing Lives (ACL) study (House, Kessler, \& Herzog, 1990; House, Lantz, \& Herd, 2005a; House et al., 1994), a stratified, multistage area 
probability sample of non-institutionalised adults age 25 and over, living in the coterminous United States, and followed over a 25 -year period. The ACL study was begun from a "stress and coping" framework to examine a broad array of indicators of health, psychosocial and behavioral functioning as individuals age through middle and late adulthood (House, Lantz, \& Herd, 2005b). To achieve the nationally representative sample, the sample design started with single counties which were stratified by region and metropolitan statistical area status and selected by probability proportionate to estimated size (PPES). Next area segments (blocks with at least 200-250 persons) were selected by PPES and finally housing units were selected from the area segments. African Americans and adults age 60 and over were over sampled. Interviews were conducted in person in the first two waves, and mainly via telephone thereafter. The first wave of the survey was conducted in 1986 with 3,617 adults. Surviving respondents were reinterviewed in 1989 ( $\mathrm{N}=2867,83 \%$ of survivors), in 1994 ( $N=2562,83 \%$ of survivors), in 2001/2002 ( $N=1787,74 \%$ of survivors), and again in 2011/2012 ( $N=1427,81 \%$ of survivors). The final analytic sample includes 3,597 participants who completed the CES-D items during at least one wave. A sampling weight is incorporated for non-response and a poststratification adjustment to the 1986 Census estimates of the US population age 25 years and older to ensure that the sample is representative of the age, gender and race distribution of the US population living in the United States in 1986 (House et al., 2005a).

\section{Measures}

The primary outcome of interest was depressive symptoms measured at each wave with an 11-item short form of the Center for Epidemiological Studies Depression Scale (CES-D) adapted by Kohout, Berkman, Evans, and Cornoni-Huntley (1993) from Radloff (1977)'s original scale. Kohout's 11-item scale was found to be reliable and contain the same fourfactor solution as the original 20-item scale. In our analyses the CES-D item "my sleep was restless" was used as a covariate to measure sleep disturbance, so a mean of the 10 remaining CES-D items was used as the measure of depressive symptoms. The Cronbach's alpha for our 10-item scale also showed strong reliability across waves ranging from .809 to .847 . The 10-item scale contains three somatic items (everything was an effort, could not get going, didn't feel like eating), three depressive affect items (felt depressed, lonely, sad), two positive affect items (feel happy, enjoy life; positive items were recoded), and two interpersonal interaction items (people dislike me, were unfriendly). Participants responded on a 1 to 3 scale indicating how frequently the symptom was experienced in the past week ( 1 = hardly ever, some of the time, or $3=$ most of the time).

To assess chronic medical conditions, participants reported whether they had a doctor's diagnosis of the following CMCs in the past 12 months: hypertension, diabetes, chronic lung disease, heart attack or other heart trouble, stroke, cancer, and arthritis. Conditions were summed for a maximum score of seven. This approach to assessing chronic conditions is utilised in many large nationally representative surveys such as the National Health and Nutrition Examination Survey (NHANES) (Schnell et al., 2012), the Longitudinal Aging Study Amsterdam (Geerlings et al., 2000), and Health and Retirement Study (HRS) (Lee, Cigolle, \& Blaum, 2009). Our count included commonly measured chronic conditions that have previously been associated with depressive symptoms (Bhattarai et al., 2013; Geerlings et al., 2000).

Sleep disturbance was measured using the CES-D item "my sleep was restless". Participants responded on a 1 to 3 scale indicating how frequently the symptom was experienced in the past week (1=hardly ever, $2=$ some of the time, or $3=$ most of the time). Though ACL does not have objective measures of sleep, prior work by the ACL study team found this CES-D item to be associated with other predictors in the same way that more detailed measures of sleep were associated with those predictors (Burgard \& Ailshire, 2009; Leggett et al., 2016).

Time-invariant demographic controls were taken from wave 1 and included age, gender, race (White, non-White), years of education and functional ability. Functional ability was assessed with a Gutman-type scale ranging from one - most severe functional impairment to four - no impairment or high functional ability. This scale was developed from items including being in a bed/chair most/all of the 
day and difficulty with bathing by oneself, climbing stairs, walking several blocks, and with heavy housework.

\section{Statistical analysis}

First, we computed descriptive statistics for all variables. We employed multilevel modeling (Littell, Milliken, Stroup, \& Wolfinger, 1996; Raudenbush \& Bryk, 2002) using SAS 9.4 PROC MIXED to examine between-person differences (person level) and within-person variability in depressive symptoms across five survey interview waves (wave level) conducted over 25 years. Raw variables were transformed into their between and within-person components prior to analysis. Predictors at the between-person level (Level 2; individual specific- $i$ ) were entered as person-specific means (an individual's average across five waves) and withinperson level (Level 1; wave by individual specific- wi) predictors were time-varying (deviations in a given wave from an individual's own mean across up to five waves) (Hoffman \& Stawski, 2009). This analysis strategy allows us to examine between-person differences in covariates (e.g. are individuals with more CMCs more depressed than individuals with less CMCs?) and also how fluctuations in covariates over time reflect within-person associations between the covariates and depressive symptoms (e.g. at a time when I have more CMCs than my average, am I more depressed?). These multilevel models utilise all waves of data that are available for an individual in the model, a useful feature as missing waves of data are common among individuals in panel studies (Raudenbush \& Bryk, 2002).

The model was built in three steps, beginning with the control variables only (model 1 ). Next, restless sleep and CMCs were added at both the betweenand within-person levels (model 2). Finally, the focal interactions were added to test for moderation (model 3). Non-significant interactions were trimmed for parsimony in the final model. The equation presented below represents the final, trimmed model. Depressive symptoms for the wth wave for the ith person are modeled as:
Level 1: Depressive symptoms $w_{w i}=\beta_{0 i}+\beta_{1 i}$ (chronic medical condition $\left.s_{w i}\right)+\beta_{2 i}\left(\right.$ restless slee $\left.p_{w i}\right)+$ $\beta_{3 i}$ (chronic medical conditions*age $\left.e_{w i}\right)+e_{w i}$

Level 2: $\beta_{0 i}=\gamma_{00}+\gamma_{01}\left(a g e_{i}\right)+\gamma_{02}\left(\right.$ gender $\left._{i}\right)+\gamma_{03}$

$\left(\right.$ ethnicity $\left._{i}\right)+\gamma_{04}\left(\right.$ education $\left._{i}\right)+\gamma_{05}$ (functional ability $)+\nu_{06}$ (chronic medical conditions $\left._{i}\right)+\gamma_{07}($ restless sleep $i)+v_{08}$ (chronic medical conditions* ${ }^{*}$ restless sleep i $_{i}$

$+u_{0 i}$

$\beta_{1 i}=\gamma_{10}$

$\beta_{2 i}=\gamma_{20}$

$\beta_{3 i}=\gamma_{30}$

(Model 3)

where the intercept $\left(B_{0 i}\right)$ represents the mean level of depressive symptoms for each individual (averaged across waves). The first slope $\left(b_{1 i}\right)$ represents the effect of chronic medical conditions at wave $w(w=1$ $5)$ on the respondent's depressive symptoms. The slope parameter $\left(B_{2 i}\right)$ represents the association of wave $W^{\prime} s$ restless sleep and $\left(B_{3 i}\right)$ reflects the association of the age by within-person level chronic medical conditions interaction with depressive symptoms. These covariates reflect deviations from an individual's own mean, and were calculated by centering around the person-mean.

At Level 2, person-mean levels of chronic medical conditions $\left(\gamma_{06}\right)$, restless sleep $\left(\nu_{07}\right)$, and the interaction between chronic medical conditions and sleep $\left(\nu_{08}\right)$ are entered as between-person covariates predicting the level of depressive symptoms at the intercept $\left(b_{0 i}\right)$. Each of these covariates indicates an individuals' average level of that characteristic across waves. Age $\left(\gamma_{01}\right)$, gender $\left(\gamma_{02}\right)$, ethnicity $\left(\gamma_{03}\right)$, education $\left(\gamma_{04}\right)$, and functional ability $\left(\gamma_{05}\right)$ were entered as baseline, between-person controls. $\gamma_{10}, \gamma_{20}$ and $\gamma_{30}$ represent the average effects of withinperson slopes from level 1 for chronic medical conditions, restless sleep and the within-person level interaction respectively. $V_{00}$ reflects the group mean level of individual depressive symptom levels and $u_{0 i}$ reflects individual deviations from that mean. 


\section{Results}

Descriptive characteristics. Full sample and crosswave descriptive results can be found in table 1 . At baseline, participants were on average 47 years old (range 24-96), 53\% were female, 17\% were nonWhite, and on average they had completed just over 12 years of education. The number of chronic medical conditions (range: 0.68-1.38) increased slightly across the waves whereas the mean depression score (range: 1.27-1.37) and restless sleep (range: 1.57-1.65) remained relatively stable.

Model 1, Demographic characteristics and depressivesSymptoms. An intraclass correlation (ICC) for depressive symptoms revealed that $56 \%$ of the variance is within-person (for the same person, across survey waves) and $44 \%$ is between-person (across respondents). Significant variability at both levels provides justification for the multi-level modeling approach. Table 2 displays results from our two-level multi-level model with coefficients and standard errors. In Model 1, person-level control adjustments revealed that individuals who were younger $\left(\nu_{01} ; B=-\right.$ $0.003, p<.001)$, female $\left(\gamma_{02} ; B=-0.043, p<.001\right)$, nonWhite ( $\left.\gamma_{03} ; B=-0.101, p<.001\right)$, less educated ( $\nu_{04} ; B=$ $-0.020, p<.001)$, and with poorer functional ability ( $\gamma_{05} ; B=-0.106, p<.001$ ) reported more depressive symptoms.

Model 2, CMC, sleep, and depressive symptoms. In model 2, we tested between- and within-person associations between the number of chronic medical conditions and restless sleep with depressive symptoms. At the wave level, respondents reported more depressive symptoms at waves when they reported more restless sleep $\left(\gamma_{20} ; B=0.123, p<.001\right)$ than their average levels. Turning to the person-level findings, individuals who on average reported more restless sleep $\left(\nu_{07} ; B=0.248, p<.001\right)$ and more CMCs ( $\gamma_{06} ; B=0.022, p<.001$ ) expressed more depressive symptoms.

Model 3, Sleep and age as moderators. In model 3, we considered whether sleep disturbance moderated the effect of CMCs on depressive symptoms. A within-person level interaction was not significant and thus trimmed from the final model for parsimony. However, a significant interaction at the between-person level was found ( $\gamma_{08} ; B=-0.017$, $p<.05)$. As displayed in figure 1 , while a higher level of chronic medical conditions was associated with a higher level of depressive symptoms among those who slept well, individuals who had restless sleep had a higher level of depressive symptoms regardless of chronic medical conditions. Additionally, in line with our second research question regarding the association between age and an individual's variability in $\mathrm{CMC}$, we found a significant interaction ( $\left.\gamma_{08} ; B=0.001, p<.001\right)$. This interaction suggests that younger adults had higher symptoms of depression at times of below average CMC relative to older adults. However this difference narrows as older adults' depressive symptoms increase with above average CMC levels (figure 2).

Sensitivity Tests. Finally, prior work has found that different CMCs have varying rates of comorbidity with depression, and sleep may impact an individual's adjustment to a more disabling CMC such as cancer relative with one that may carry less symptomatology such as hypertension. Therefore as a sensitivity test we also tested an interaction between sleep and each individual CMC. Only one interaction was significant at the individual level- heart attack and other heart trouble $(B=-0.049, p<.01)$, which is consistent with a large literature showing a strong association between cardiovascular disease and depression. However, examining the interactions individually, as opposed to our sum score reflecting multimorbidity, reduced the power to detect other interactive effects.

\section{Discussion}

Using a nationally-representative sample of adults from the ACL study, we found that similar to the findings of previous studies (Baglioni et al., 2011; Maglione et al., 2012), sleep disturbance was associated with depression even controlling for $\mathrm{CMC}$ and other risk factors. Additionally, sleep disturbance moderated the association between CMCs and depressive symptoms. In particular, more CMCs were clearly linked to higher depressive symptoms among individuals sleeping well; however among individuals reporting poor sleep, depressive symptoms were higher regardless of $\mathrm{CMC}$.

Sleep disturbance has proven treatments, and improvements in sleep may reduce the strength of association between CMCs and depression, and potentially the symptoms of CMCs. There are several 
reasons why the combination of sleep and morbidity may have implications for depression. First, Devins et al. (1993) found that sleep disturbance was associated with the "intrusiveness" of one's CMC into daily life. Greater severity of illness may also pose greater challenge to mental stability or even lead to despair if one is not able to adequately adjust. In addition, both sleep disturbance and CMC may be prodromal symptoms or early risk factors for depressive illness, with the compounding of risk leading to greater likelihood of developing depressive illness over time. In line with this hypothesis, future work should consider the moderating impact on development of depression, in other words controlling for baseline depression status. The underlying, putative mechanisms relating to the development of depression may include inflammation, intrusiveness and necessity to adapt to an illness, stress, reduced functioning, pain or another complication of lack of sleep and morbidity (Devins et al., 1993; Konsman et al., 2002; Parish, 2009; Smith \& Haythornthwaite, 2004). However, the compounding of these issues likely increases one's risk for increased depressed mood.

We also found support for a second research question regarding whether age alters the effect of $\mathrm{CMC}$ on depression. Younger adults had higher levels of depressive symptoms at waves in which they had fewer CMCs than their personal average across the waves. Though one might expect above average CMCs to be associated with depression, this finding may reflect the high stress that comes with an initial chronic medical conditions diagnosis and the fact that chronic medical conditions are less anticipated at younger ages. As individuals age and as CMCs accumulate, coping strategies and outlooks on the illness context may shift. Younger adults may learn to cope more adaptively over time as the initial shock of an illness fades. In addition, our sensitivity test of the moderation of sleep disturbance on the effects of individual CMCs was likely limited due to a lack of power when examining each illness separately. However, a heart trouble or heart attack interaction with sleep was found suggesting that individuals who are sleeping poorly and have heart trouble are at particular risk for depressive symptoms. Future work examining distinct categories of $\mathrm{CMC}$ based on symptomatology, pain, or chronicity in interaction with sleep disturbance may be fruitful to further unpack these associations.

This study has a number of strengths, including a 25-year longitudinal design that allows for examination of between and within-person effects and a nationally representative sample of adults in the United States. However, several limitations to the current study should be noted. The only assessment of sleep available across the five study waves was the single item from the CES-D scale capturing restless sleep. Additional items measuring adequacy of sleep were only added in the most recent measurement wave. Therefore future work should consider validated sleep scales or objective measures of sleep disturbance in relation to CMC and depression. As restless sleep and depressive symptoms were measured in the same wave as distinctive components of the CES-D index, it follows that these constructs will be correlated. However, our key question was to determine whether sleep might moderate the association between $\mathrm{CMC}$ and depressive symptoms over time, which our longitudinal, nationally representative data allowed us to consider. It is important to note, however, that a causal link or mediation between sleep and depressive symptoms should not be implied from our findings. Despite the limited one item assessment, prior work has found it to be valid and associated with other predictors in the same way as more extensive sleep measures (Burgard \& Ailshire, 2009; Leggett et al., 2016). It is likely that some attrition across study waves is due to CMC and mental illness; however, a strength of the multi-level design is to use all available data waves and thus not exclude individuals who attrited over time. Finally, it is important to note that as we tested our interaction by calculating the significance of multiplicative terms between CMC and sleep disturbance, we cannot statistically distinguish the main effect from the moderator. However, in our conceptual model, CMC and sleep were the main predictor and moderator, respectively. This decision was based on prior research of sleep as a moderator of several risk factors on psychological outcomes, as well as the modifiable nature of sleep disturbance relative to CMC. 


\section{Conclusion}

In conclusion, in a nationally representative adult US sample, individuals sleeping poorly were more depressed regardless of CMCs. However, among those sleeping well, CMCs were more clearly linked to increased risk of depression, while those free of CMCs were less depressed. Early detection of sleep disturbance among individuals with $\mathrm{CMC}$ and preventative pharmacological or behavioral sleep interventions may help to alter both physical and mental health trajectories toward more positive outcomes over time. Further, Bhattarai et al. (2013) found that morbidities combined with comorbidity of depression led to increasing rates of drug prescriptions, primary care consultations, specialist visits, and in-patient hospital visits. The presence of depression at any level of morbidity was associated with increased healthcare utilisation. Given the high utilisation of the health care system among individuals with $\mathrm{CMC}$, depression, and sleep disturbance, early screening and treatment of sleep disturbance may reduce system costs and have enduring public health benefit.

\section{Acknowledgements}

This work was supported by the Department of Veterans Affairs (K.Z., IIR 10-176).

\section{References}

Alexopoulos, G. S., Meyers, B. S., Young, R. C., Campbell, S., Silbersweig, D., \& Charlson, M. (1997). 'Vascular depression' hypothesis. Archives of General Psychiatry, 54(10), 915-922. https://doi.org/10.1001/archpsyc.1997.01830220033006

Anderson, G. (2010). Chronic care: Making the case for ongoing care. Retrieved from Princeton, NJ: www.rwjf.org/pr/product.jsp?id-50968

Baglioni, C., Battagliese, G., Feige, B., Spiegelhalder, K., Nissen, C., Voderholzer, U., . . Riemann, D. (2011). Insomnia as a predictor of depression: A meta-analytic evaluation of longitudinal epidemiological studies. Journal of Affective Disorders, 135(1-3), 10-19. https://doi.org/10.1016/j.jad.2011.01.011

Berg, C. A., \& Upchurch, R. (2007). A developmental-contextual model of couples coping with chronic illness across the adult life span. Psychological Bulletin, 133(6), 920-954. https://doi.org/10.1037/0033-2909.133.6.920

Berger, A. M. (2009). Update on the state of the science: sleep-wake disturbances in adult patients with cancer. Paper presented at the Oncology Nursing Forum. https://doi.org/10.1188/09.ONF.E165-E177

Berger, A. M., \& Mitchell, S. A. (2008). Modifying Cancer-Related Fatigue by Optimizing Sleep Quality. Journal of the National Comprehensive Cancer Network, 6(1), 3-13.

Bhattarai, N., Charlton, J., Rudisill, C., \& Gulliford, M. C. (2013). Prevalence of depression and utilization of health care in single and multiple morbidity: a population-based cohort study. Psychological Medicine, 43(07), 1423-1431. https://doi.org/10.1017/S0033291712002498

Bower, J. E. (2008). Behavioral Symptoms in Patients With Breast Cancer and Survivors. Journal of Clinical Oncology, 26(5), 768-777. https://doi.org/10.1200/JCO.2007.14.3248

Brandtstädter, J., \& Greve, W. (1994). The Aging Self: Stabilizing and Protective Processes. Developmental Review, 14(1), 52-80. https://doi.org/10.1006/drev.1994.1003

Burgard, S. A., \& Ailshire, J. A. (2009). Putting Work to Bed: Stressful Experiences on the Job and Sleep Quality. Journal of Health and Social Behavior, 50(4), 476-492. https://doi.org/10.2307/20617656

Carpenter, J. S., Elam, J. L., Ridner, S. H., Carney, P. H., Cherry, G. J., \& Cucullu, H. L. (2004). Sleep, fatigue, and depressive symptoms in breast cancer survivors and matched healthy women experiencing hot flashes. Paper presented at the Oncology Nursing Forum. https://doi.org/10.1188/04.ONF.591-598

Devins, G. M., Edworthy, S. M., Paul, L. C., Mandin, H., Seland, T. P., Klein, G., . . Shapiro, C. M. (1993). Restless sleep, illness intrusiveness, and depressive symptoms in three chronic illness conditions: Rheumatoid 
arthritis, end-stage renal disease, and multiple sclerosis. Journal of Psychosomatic Research, 37(2), 163-

170. http://dx.doi.org/10.1016/0022-3999(93)90083-R

Diehl, M., Coyle, N., \& Labouvie-Vief, G. (1996). Age and sex differences in strategies of coping and defense across the life span. Psychology and Aging, 11(1), 127-139. https://doi.org/10.1037/0882-7974.11.1.127

Egede, L. E. (2007). Major depression in individuals with chronic medical disorders: prevalence, correlates and association with health resource utilization, lost productivity and functional disability. General Hospital Psychiatry, 29(5), 409-416. https://doi.org/10.1016/j.genhosppsych.2007.06.002

Felton, B. J., \& Revenson, T. A. (1987). Age differences in coping with chronic illness. Psychology and Aging, 2(2), 164-170. https://doi.org/10.1037/0882-7974.2.2.164

Folkman, S., Lazarus, R. S., Pimley, S., \& Novacek, J. (1987). Age differences in stress and coping processes. Psychology and Aging, 2(2), 171-184. https://doi.org/10.1037/0882-7974.2.2.171

Geerlings, S. W., Beekman, A. T., Deeg, D. J., \& Van Tilburg, W. (2000). Physical health and the onset and persistence of depression in older adults: an eight-wave prospective community-based study. Psychological Medicine, 30(2), 369-380. https://doi.org/10.1017/S0033291799001890

Hamilton, N. A., Catley, D., \& Karlson, C. (2007). Sleep and the affective response to stress and pain. Health Psychology, 26(3), 288-295. https://doi.org/10.1037/0278-6133.26.3.288

Heckhausen, J., \& Schulz, R. (1995). A life-span theory of control. Psychological Review, 102(2), 284-304. https://doi.org/10.1037/0033-295X.102.2.284

Hoffman, L., \& Stawski, R. (2009). Persons as Contexts: Evaluating Between-Person and Within-Person Effects in Longitudinal Analysis. Research in Human Development, 6(2), 97-120. https://doi.org/10.1080/15427600902911189

House, J. S., Kessler, R. C., \& Herzog, A. R. (1990). Age, Socioeconomic Status, and Health. The Milbank Quarterly, 68(3), 383-411. https://doi.org/10.2307/3350111

House, J. S., Lantz, P. M., \& Herd, P. (2005a). Continuity and Change in the Social Stratification of Aging and Health Over the Life Course: Evidence From a Nationally Representative Longitudinal Study From 1986 to 2001/2002 (Americans' Changing Lives Study). The Journals of Gerontology Series B: Psychological Sciences and Social Sciences, 60(Special Issue 2), S15-S26. https://doi.org/10.1093/geronb/60.Special_Issue_2.S15

House, J. S., Lantz, P. M., \& Herd, P. (2005b). Continuity and change in the social stratification of aging and health over the life course: Evidence from a nationally representative longitudinal study from 1986 to 2001/2002 (Americans' changing lives study). The Journals of Gerontology: Series B: Psychological Sciences and Social Sciences, 60(Suppl 2), 15-26. https://doi.org/10.1093/geronb/60.Special_Issue_2.S15

House, J. S., Lepkowski, J. M., Kinney, A. M., Mero, R. P., Kessler, R. C., \& Herzog, A. R. (1994). The Social Stratification of Aging and Health. Journal of Health and Social Behavior, 35(3), 213-234. https://doi.org/10.2307/2137277

Katon, W. J. (2003). Clinical and health services relationships between major depression, depressive symptoms, and general medical illness. Biological Psychiatry, 54(3), 216-226. https://doi.org/10.1016/S00063223(03)00273-7

Katz, D. A., \& McHorney, C. A. (2002). The relationship between insomnia and health-related quality of life in patients with chronic illness. Journal of Family Practice, 51(3), 229-236.

Kohout, F. J., Berkman, L. F., Evans, D. A., \& Cornoni-Huntley, J. (1993). Two shorter forms of the CES-D (Center for Epidemiological Studies Depression) depression symptoms index. The Journal of Aging and Health, 5(2), 179-193. https://doi.org/10.1177/089826439300500202

Konsman, J. P., Parnet, P., \& Dantzer, R. (2002). Cytokine-induced sickness behaviour: mechanisms and implications. Trends in Neurosciences, 25(3), 154-159. https://doi.org/10.1016/S0166-2236(00)02088-9

Lee, P. G., Cigolle, C., \& Blaum, C. (2009). The Co-Occurrence of Chronic Diseases and Geriatric Syndromes: The Health and Retirement Study. Journal of the American Geriatrics Society, 57(3), 511-516. https://doi.org/10.1111/j.1532-5415.2008.02150.x 
Leggett, A., Burgard, S., \& Zivin, K. (2016). The Impact of Sleep Disturbance on the Association Between Stressful Life Events and Depressive Symptoms. The Journals of Gerontology Series B Psychological Sciences and Social Sciences, 71(1), 118-128. https://doi.org/10.1093/geronb/gbv072

Lehnert, T., Heider, D., Leicht, H., Heinrich, S., Corrieri, S., Luppa, M., Riedel-Heller, S., \& PLEASE ADD ANY MISSING AUTORS König, H.-H. (2011). Review: Health Care Utilization and Costs of Elderly Persons With Multiple Chronic Conditions. Medical Care Research and Review, 68(4), 387-420. https://doi.org/10.1177/1077558711399580

Littell, R. C., Milliken, G. A., Stroup, W. W., \& Wolfinger, R. D. (1996). SAS system for mixed models. Cary, NC: SAS Institute Inc.

Maglione, J. E., Ancoli-Israel, S., Peters, K. W., Paudel, M. L., Yaffe, K., Ensrud, K. E., \& Stone, K. L. (2012). Depressive symptoms and subjective and objective sleep in community-dwelling older women. Journal of the American Geriatrics Society, 60(4), 635-643. https://doi.org/10.1111/j.1532-5415.2012.03908.x

Moussavi, S., Chatterji, S., Verdes, E., Tandon, A., Patel, V., \& Ustun, B. (2007). Depression, chronic diseases, and decrements in health: results from the World Health Surveys. Lancet, 370(9590), 851-858. https://doi.org/10.1016/S0140-6736(07)61415-9

Ormel, J., Rijsdijk, F. V., Sullivan, M., van Sonderen, E., \& Kempen, G. (2002). Temporal and reciprocal relationship between IADL/ADL disability and depressive symptoms in late life. Journals of Gerontology Series BPsychological Sciences and Social Sciences, 57(4), 338-347. https://doi.org/10.1093/geronb/57.4.P338

Parish, J. M. (2009). Sleep-related problems in common medical conditions. Chest, 135(2), 563-572. https://doi.org/10.1378/chest.08-0934

Radloff, L. (1977). The CES-D scale: a self-report depression scale for research in the general population. Applied Psychological Measurement, 1(3), 385-401. https://doi.org/10.1177/014662167700100306

Raudenbush, S. W., \& Bryk, A. S. (2002). Hierarchical linear models: Applications and data analysis methods (2 ed.). London, England: Sage.

Sanz-Vergel, A. I., Demerouti, E., Mayo, M., \& Moreno-Jiménez, B. (2011). Work-home interaction and psychological strain: The moderating role of sleep quality. Applied Psychology, 60(2), 210-230. https://doi.org/10.1111/j.1464-0597.2010.00433.x

Schnell, K., Weiss, C. O., Lee, T., Krishnan, J. A., Leff, B., Wolff, J. L., \& Boyd, C. (2012). The prevalence of clinicallyrelevant comorbid conditions in patients with physician-diagnosed COPD: a cross-sectional study using data from NHANES 1999-2008. BMC Pulmonary Medicine, 12(1), 26. https://doi.org/10.1186/1471-2466-12-26

Schnittker, J. (2005). Chronic illness and depressive symptoms in late life. Social Science \& Medicine, 60(1), 13-23. https://doi.org/10.1016/j.socscimed.2004.04.020

Sherbourne, C. D., Meredith, L. S., Rogers, W., \& Ware, J. E. (1992). Social support and stressful life events: age differences in their effects on health-related quality of life among the chronically ill. Quality of Life Research, 1(4), 235-246. https://doi.org/10.1007/BF00435632

Smith, M. T., \& Haythornthwaite, J. A. (2004). How do sleep disturbance and chronic pain inter-relate? Insights from the longitudinal and cognitive-behavioral clinical trials literature. Sleep Medicine Reviews, 8(2), 119-132. https://doi.org/10.1016/S1087-0792(03)00044-3

Taylor, D. J., Mallory, L. J., Lichstein, K. L., Durrence, H., Riedel, B. W., \& Bush, A. J. (2007). Comorbidity of chronic insomnia with medical problems. SLEEP-NEW YORK THEN WESTCHESTER-, 30(2), 213.

Vogeli, C., Shields, A., Lee, T., Gibson, T., Marder, W., Weiss, K., \& Blumenthal, D. (2007). Multiple Chronic Conditions: Prevalence, Health Consequences, and Implications for Quality, Care Management, and Costs. Journal of General Internal Medicine, 22(3), 391-395. https://doi.org/10.1007/s11606-007-0322-1

Wielgus, K. K., Berger, A. M., \& Hertzog, M. (2009). Predictors of fatigue 30 days after completing anthracycline plus taxane adjuvant chemotherapy for breast cancer. Paper presented at the Oncology Nursing Forum. https://doi.org/10.1188/09.ONF.38-48 
Table 1. Sample characteristics and comparison of key variables across waves

\begin{tabular}{|c|c|c|c|c|c|}
\hline & $\begin{array}{c}\text { Wave } 1 \\
(1986)\end{array}$ & $\begin{array}{c}\text { Wave } 2 \\
(1989)\end{array}$ & $\begin{array}{c}\text { Wave } 3 \\
(1994)\end{array}$ & $\begin{array}{c}\text { Wave } 4 \\
(2001 / 2)\end{array}$ & $\begin{array}{c}\text { Wave } 5 \\
(2011)\end{array}$ \\
\hline \multicolumn{6}{|l|}{ Age } \\
\hline Mean & 47.11 & & & & \\
\hline Range & $24-96$ & & & & \\
\hline SD & 16.45 & & & & \\
\hline Female (\%) & $52.9 \%$ & & & & \\
\hline \multicolumn{6}{|l|}{ Education (years) } \\
\hline Mean & 12.36 & & & & \\
\hline Range & $0-17$ & & & & \\
\hline SD & 3.14 & & & & \\
\hline Non-White (\%) & $16.5 \%$ & & & & \\
\hline Functional ability & $N=3617$ & $N=2867$ & $N=2559$ & $N=1785$ & $N=1427$ \\
\hline Mean & 3.73 & 3.74 & 3.66 & 3.64 & 3.46 \\
\hline Range & $1-4$ & $1-4$ & $1-4$ & $1-4$ & $1-4$ \\
\hline SD & 0.70 & 0.70 & 0.87 & 0.93 & 1.18 \\
\hline Chronic medical conditions & $N=3617$ & $N=2867$ & $N=2559$ & $N=1688$ & $N=1164$ \\
\hline Mean & 0.68 & 0.70 & 0.83 & 0.88 & 1.38 \\
\hline Range & $0-5$ & $0-6$ & $0-6$ & $0-6$ & $0-5$ \\
\hline SD & 0.96 & 0.99 & 1.06 & 1.09 & 1.12 \\
\hline Restless sleep & $N=3585$ & $N=2852$ & $N=2390$ & $N=1682$ & $N=1316$ \\
\hline Mean & 1.65 & 1.61 & 1.57 & 1.62 & 1.59 \\
\hline Range & $1-3$ & $1-3$ & $1-3$ & $1-3$ & $1-3$ \\
\hline SD & 0.70 & 0.67 & 0.74 & 0.78 & 0.82 \\
\hline CES-D 10 & $N=3605$ & $N=2859$ & $N=2394$ & $N=1682$ & $N=1316$ \\
\hline Item Mean & 1.37 & 1.34 & 1.28 & 1.27 & 1.28 \\
\hline Range & $1-2.9$ & $1-2.9$ & $1-3$ & $1-2.8$ & $1-3$ \\
\hline SD & 0.35 & 0.35 & 0.34 & 0.35 & 0.40 \\
\hline
\end{tabular}

Note. Descriptive statistics are weighted. 
Table 2. Linear mixed model of demographic and health characteristics, sleep disturbance, and chronic medical conditions on depressive symptoms

\begin{tabular}{|c|c|c|c|c|c|c|}
\hline & \multicolumn{6}{|c|}{ Depressive Mood } \\
\hline & \multicolumn{2}{|c|}{ Model 1} & \multicolumn{2}{|c|}{ Model 2} & \multicolumn{2}{|c|}{ Model 3} \\
\hline & $B$ & $(S E)$ & $B$ & $(S E)$ & $B$ & $(S E)$ \\
\hline \multicolumn{7}{|l|}{ Fixed Effects } \\
\hline Intercept, $Y_{0 o}$ & $2.21 * * *$ & $(0.038)$ & $1.51 * * *$ & $(0.040)$ & $1.49 * * *$ & $(0.041)$ \\
\hline \multicolumn{7}{|l|}{ Within-Person Covariates $^{a}$} \\
\hline Chronic Medical Conditions (CMC), $\gamma_{10}$ & -- & -- & -0.002 & $(0.004)$ & $-0.045^{* * *}$ & $(0.013)$ \\
\hline Restless Sleep, $\gamma_{20}$ & -- & -- & $0.123 * * *$ & $(0.005)$ & $0.123 * * *$ & $(0.005)$ \\
\hline $\mathrm{CMC}^{*} \mathrm{Age}, \gamma_{30}$ & -- & -- & -- & -- & $0.001 * * *$ & $(0.0003)$ \\
\hline \multicolumn{7}{|l|}{ Between-Person Covariates $^{b}$} \\
\hline Age, $Y_{01}$ & $-0.003 * * *$ & $(0.0003)$ & $-0.002 * * *$ & $(0.0003)$ & $-0.002 * * *$ & $(0.0002)$ \\
\hline Male, $Y_{02}$ & $-0.043 * * *$ & $(0.009)$ & $-0.021^{*}$ & $(0.008)$ & $-0.020 *$ & $(0.008)$ \\
\hline White, $\gamma_{03}$ & $-0.101 * * *$ & $(0.011)$ & $-0.093 * * *$ & $(0.010)$ & $-0.092 * * *$ & $(0.010)$ \\
\hline Education, $Y_{04}$ & $-0.020 * * *$ & $(0.002)$ & $-0.015 * * *$ & $(0.001)$ & $-0.015^{* * *}$ & $(0.001)$ \\
\hline Functional Ability, $Y_{05}$ & $-0.106 * * *$ & $(0.007)$ & $-0.058 * * *$ & $(0.006)$ & $-0.060 * * *$ & $(0.006)$ \\
\hline $\mathrm{CMC}, \mathrm{Y}_{06}$ & -- & -- & $0.022 * * *$ & $(0.006)$ & $0.053^{* * *}$ & $(0.015)$ \\
\hline Restless Sleep, $Y_{07}$ & -- & -- & $0.248 * * *$ & $(0.008)$ & $0.267 * * *$ & $(0.012)$ \\
\hline CMC*Sleep, $V_{08}$ & -- & -- & -- & -- & $-0.017^{*}$ & $(0.008)$ \\
\hline \multicolumn{7}{|l|}{ Random Effects } \\
\hline Intercept, $\sigma_{u 0}^{2}$ & $0.041 * * *$ & $(0.002)$ & $0.027 * * *$ & $(0.001)$ & $0.027^{* * *}$ & $(0.001)$ \\
\hline Residual, $\sigma_{e 1}^{2}$ & $0.065 * * *$ & $(0.001)$ & $0.059 * * *$ & $(0.001)$ & $0.059 * * *$ & $(0.001)$ \\
\hline-2 Log Likelihood & 7951.3 & & 6211.0 & & 6216.6 & \\
\hline
\end{tabular}

Notes. Step 1: Participant $N=3,605$, Observation $N=11,834$; Step 2 \& 3: Participant $N=3,597$, Observation $N=11,546$. ${ }^{a}$ Person-mean centered scores (i.e., time-varying). ${ }^{\mathrm{b}}$ Person-mean across waves (i.e., time-invariant). ${ }^{*} p<.05 .{ }^{* *} p<.01 .{ }^{* * *} p<.001$ 
Figure 1. Restless sleep as a significant moderator of the chronic medical conditions and depressive symptom association (Between-person level interaction, $Y_{08}$ )

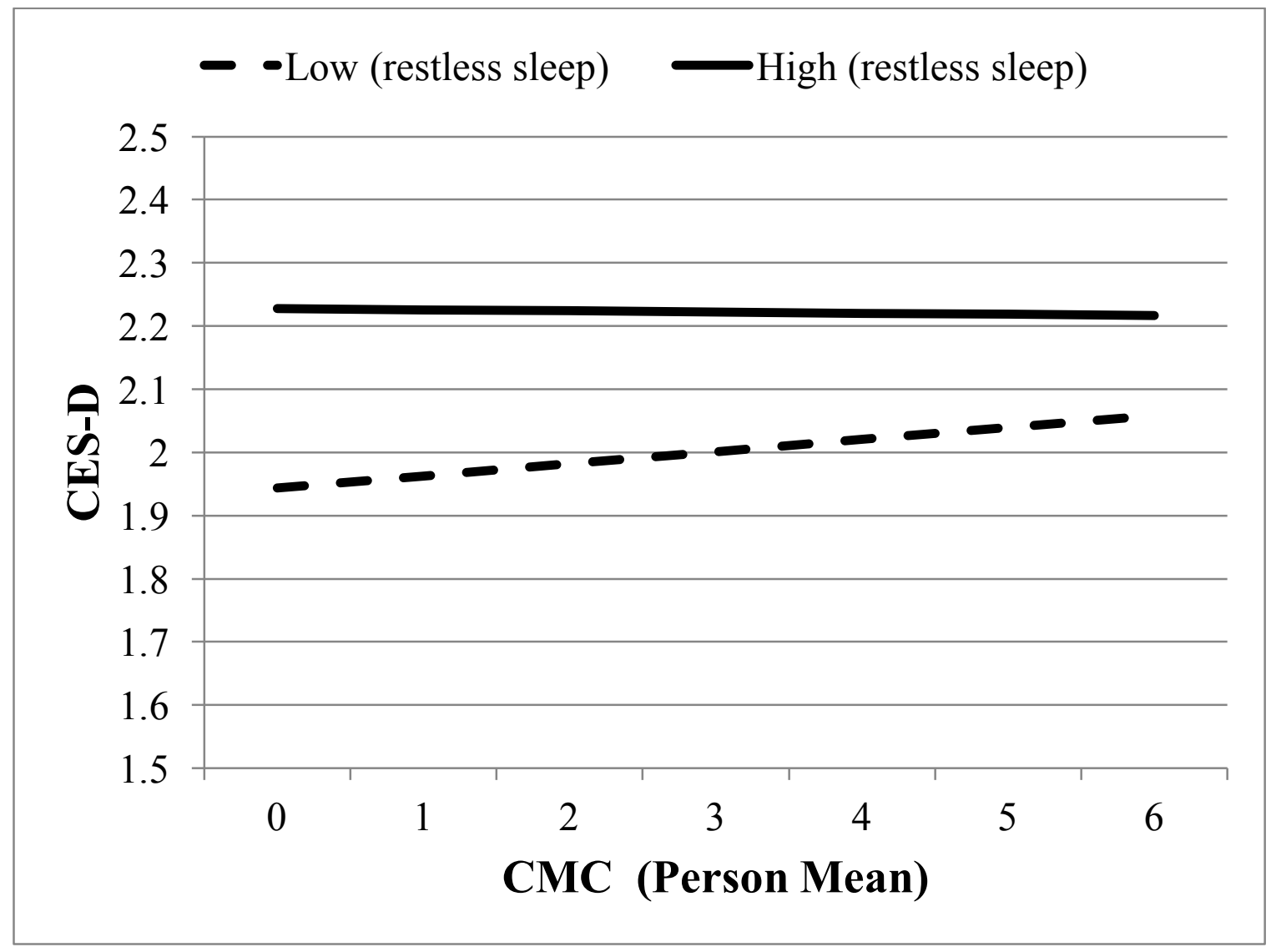

Notes. High and low restless sleep indicating 1 SD above and below the overall sample (between-person level) mean. Chronic medical conditions reflect the summed total range of the sample. 
Figure 2. Age as a significant moderator of the chronic medical conditions and depressive symptom association (Within-person level interaction, $\gamma_{30}$ )

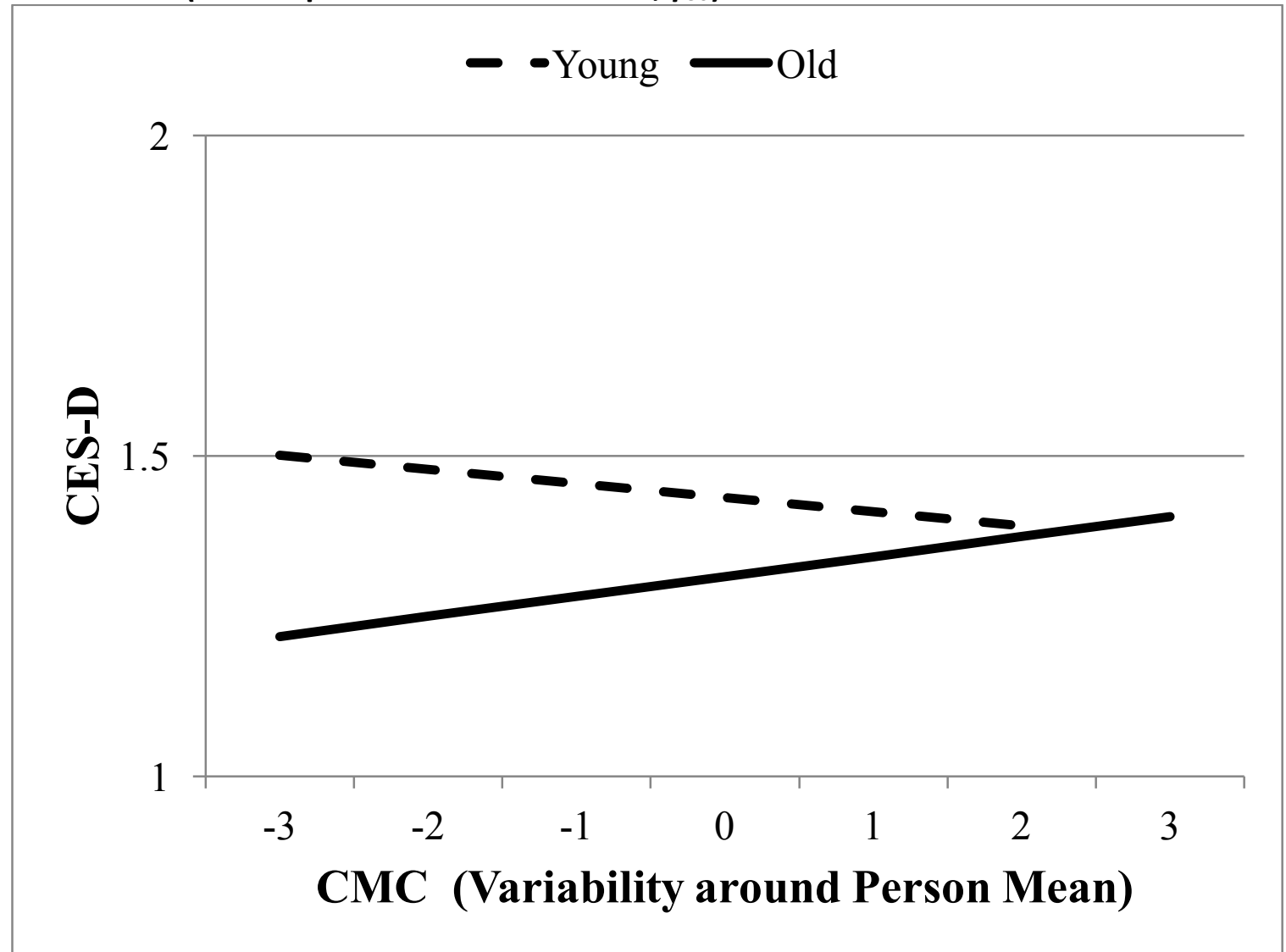

Notes. Young represents 2 SD below the sample mean (age 25) and 2 SD above the sample mean (age 81). Chronic medical conditions variability around an individual's person mean with zero reflecting the person mean, a positive number reflecting an above average wave and a negative number reflecting a below average wave. 